\title{
ANALISIS KEKUATAN MEKANIK WATER COOLING TANK PADA FASILITAS UJI UNTAI PASSIF-02 MENGGUNAKAN CATIA
}

\author{
D. Haryanto ${ }^{1, *}$, Giarno ${ }^{1}$, J. Prasetio W. ${ }^{1}$, S. Hatmoko ${ }^{1}$, K. Santosa ${ }^{1}$, M. Juarsa ${ }^{1}$, \\ M.H. Kusuma ${ }^{1}$, A. R. Antariksawan ${ }^{1}$ dan N. Putra ${ }^{2}$ \\ ${ }^{1}$ Pusat Teknologi dan Keselamatan Reaktor Nuklir, Badan Tenaga Nuklir Nasional \\ ${ }^{2}$ Laboratorium Perpindahan Kalor, Departemen Teknik Mesin, FT UI \\ email: dedy.haryanto@batan.go.id
}

\begin{abstract}
Strand Test Facility has been constructed and will be used for passive reactor core cooling simulation research without using a pump or outside force, so that the movement of water flow occurs naturally. One important component of the FASSIP-02 is the water cooling tank (WCT), in addition to piping, expansion tanks (ET) and water heating tanks (WHT). WCT containing water such as a pond that functions to take heat in the water from the FASSIP-02 piping system with a position at an altitude of 11 meters. The total load of water and tank is 10 tons and for safety and security factors during operation it is necessary to analyze the mechanical strength of the WCT. Analysis is done by simulating mechanical stress conditions and translational displacement to determine the safety of WCT when operating. The stages of analysis include making a 3-dimensional model equipped with the mechanical properties of the material used, giving a load on the 3-dimensional WCT model, giving restrain to simulate the stable condition of the 3-dimensional model and testing it in simulation. The results of the analysis show that the mechanical stress on the WCT is still in the elastic area of the Carbon Steel AISI 1040 material if the temperature of the secondary water in WCT is less than $90^{\circ} \mathrm{C}$. The primary water operating temperature is a maximum of $90^{\circ} \mathrm{C}$ and the secondary water temperature does not reach $90^{\circ} \mathrm{C}$ due to heat transfer from primary to secondary. Translational displacement that occurs is very small when compared to the WCT dimension so that it does not result in a change in shape in the WCT. Thus the design of the WCT can be continued to be constructed and safely operated.
\end{abstract}

Keywords: FASSIP-02, water cooling tank, voltage, mechanical, translational displacement

\section{PENDAHULUAN}

Untai FAsilitas Simulasi SIstem Pasif-02 (FASSIP-02) merupakan fasilitas uji eksperimen sistem pendingin pasif untuk pengambilan panas sisa hasil peluruhan yang dihasilkan oleh teras reaktor selama kondisi kecelakaan. Penelitian sistem pasif ini dilakukan berdasarkan kejadian kecelakaan parah pada pembangkit tenaga nuklir Fukushima Dai-ichi di Jepang pada tahun 2011. Kecelakaan reaktor yang disebabkan oleh gagalnya sistem pendingin aktif membuang panas sisa hasil peluruhan yang dihasilkan. Station Black Out (SBO) terjadi karena tsunami merendam kawasan reaktor dan menyebabkan generator diesel tidak dapat difungsikan sebagaimana mestinya yang mengakibatkan sistem pendingin aktif tidak dapat bekerja untuk membuang kalor [1-5]. Komponen pada Untai FASSIP-02 terdiri dari water heating tank (WHT), pemipaan, expansion tank (ET) dan water cooling tank (WCT). Untai FASSIP-02 digunakan untuk penelitian pendinginan pada teras reaktor tanpa menggunakan catu daya listrik, sehingga sirkulasi air yang terjadi diakibatkan karena adanya perbedaan kerapatannya . Water heating tank berfungsi untuk mensimulasikan teras reaktor sebagai pembangkit kalor, dimana kalor yang dihasilkan mengakibatkan temperatur air meningkat. Sehingga kerapatannya menjadi turun dan air akan mengalir ke atas menuju WCT. Selanjutnya WCT berfungsi mengambil kalor pada air sehingga temperatur air menurun dan berakibat kerapatan air naik, sehingga air akan mengalir ke bawah menuju ke WHT [6-8].

Sebelum Untai FASSIP-02 dikonstruksi dan dioperasikan perlu dilakukan analisis untuk mengetahui keamanan dan keandalan komponen yang akan dibuat. Penelitian ini difokuskan pada analisis kekuatan mekanik pada WCT yang meliputi tegangan mekanik dan translational displacement. Hasil analisis yang didapatkan akan digunakan untuk mengetahui kekuatan mekanik WCT yang akan dikonstruksi dan dioperasikan. Analisis dilakukan secara simulasi menggunakan software Computer Aided Three-dimensional Interactive Application (CATIA) [9]. Software ini terbukti akurat untuk mengetahui kekuatan mekanik struktur, dan software ini juga pernah 
digunakan untuk menganalisis struktur eksperimen kanal, rancangan kit holder pada mesin universal gerinding RUP/1500 dan menganalisis kekuatan mekanik pada struktur UUTR [10-12].

Tahapan analisis kekuatan mekanik pada WCT meliputi pembuatan model 3-dimensi dilengkapi dengan sifat-sifat mekanik material yang digunakan, pemberian beban pada model 3dimensi WCT, pemberian restrain untuk mensimulasikan kondisi stabil model 3-dimensi dan melakukan pengujian secara simulasi. Besar tegangan mekanik yang diperoleh dari pengujian secara simulasi dibandingkan dengan yield strength material yang digunakan. Sedangkan besar translational displacement yang diperoleh tidak dikehendaki terlalu besar sehingga dapat merubah bentuk dan dimensi WCT.

\section{METODOLOGI}

\section{Desain Water Cooling Tank}

Water Cooling Tank (WCT) merupakan salah satu komponen pada FASSIP-02 yang berfungsi untuk mengambil kalor pada air sehingga kerapatan air meningkat. WCT mempunyai air primer (air didalam pipa untai FASSIP-02) dan air sekunder (air yang merendam pipa untai FASSIP-02). Air sekunder berfungsi untuk mengambil kalor pada air primer. Pada untai FASSIP02, WCT diletakkan pada ketinggian 11 meter sehingga jika terjadi peningkatan kerapatan air maka air akan mengalir menuju Water Heating Tank (WHT) yang diletakkan pada level 0 mm seperti yang terlihat pada Gambar 1 berikut [13-15].

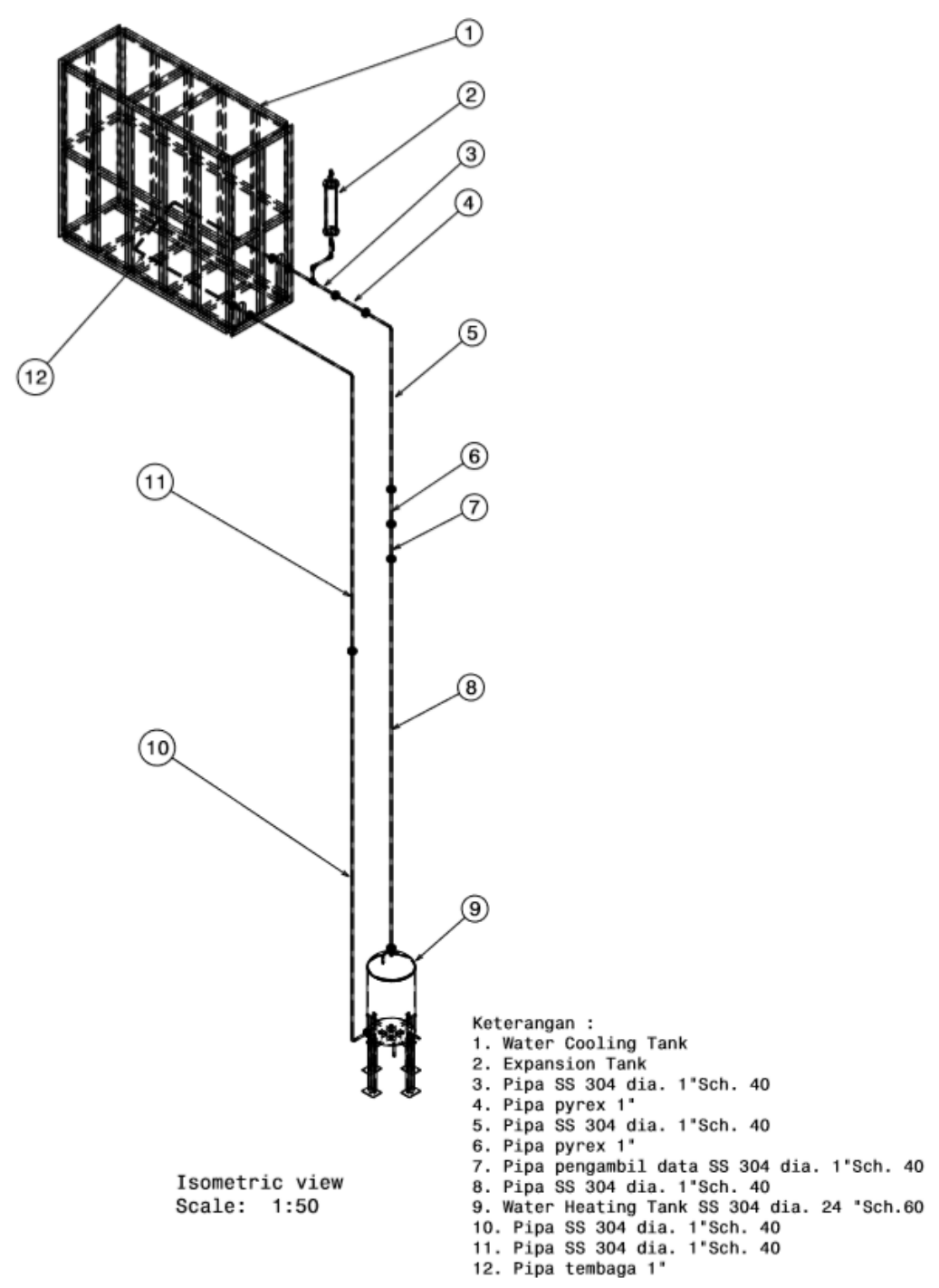

Gambar 1. Desain Untai FASSIP-02 [13-15]. 
WCT didesain bermaterial Carbon Steel AISI 1040 dengan dimensi panjang $3000 \mathrm{~mm}$ lebar $1000 \mathrm{~mm}$ dan tinggi $2750 \mathrm{~mm}$ serta ketebalan pelat $6 \mathrm{~mm}$. Untuk memperkuat terhadap tekanan air yang ditampung WCT dilengkapi dengan support menggunakan besi profil $\mathrm{U}$ atau biasa disebut UNP $100 \times 50 \times 5 \mathrm{~mm}$, serta dilengkapi pula dengan pipa tembaga (sebagai pipa air primer) berbentuk $U$ berdiameter 1 inchi dan terpasang dengan kemiringan $30^{\circ}$ seperti yang terlihat pada Gambar 2.
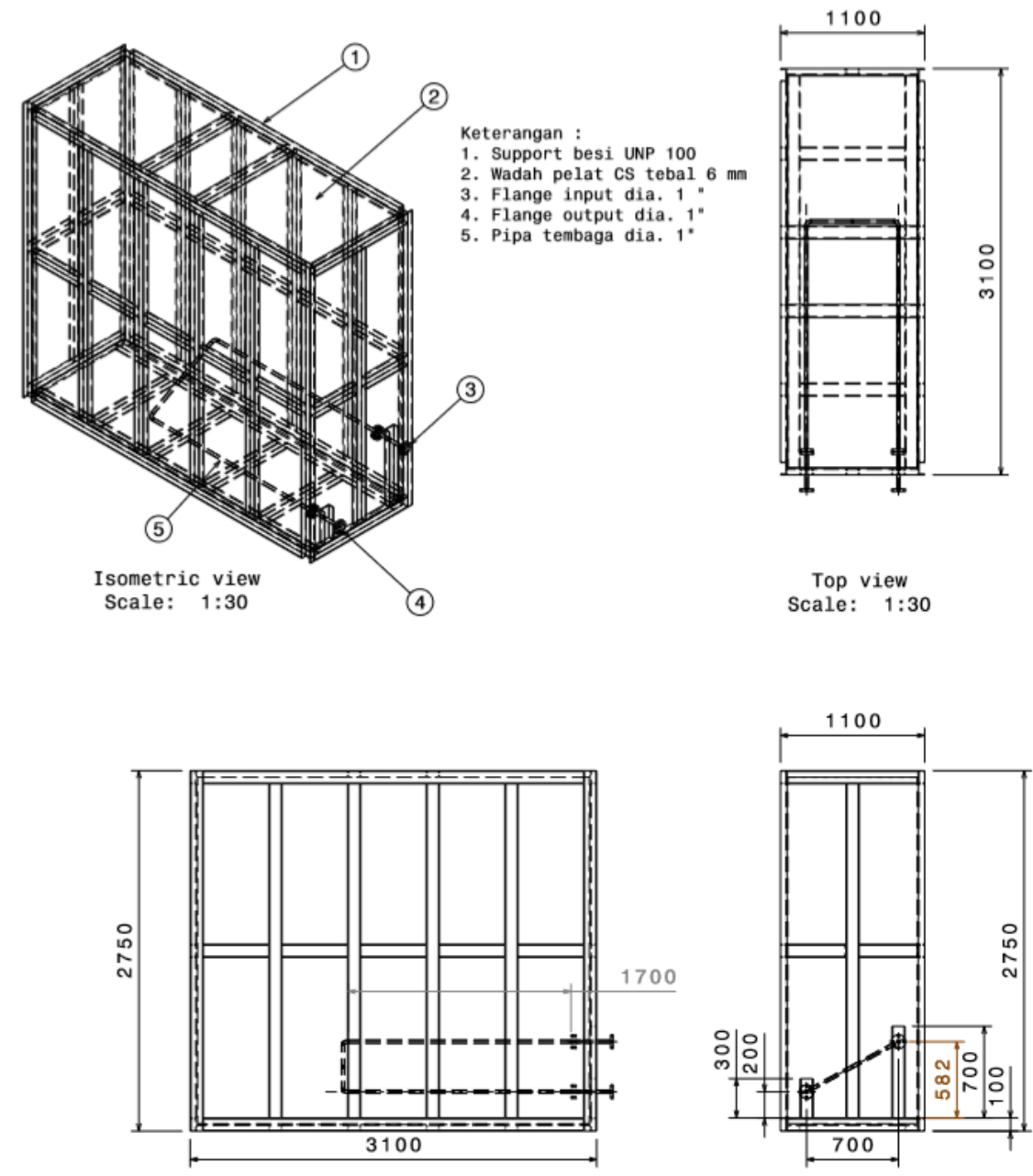

$$
\begin{array}{ll}
\text { Left view } \\
\text { Scale: } 1: 30
\end{array}
$$$$
\begin{array}{cc}
\text { Front view } \\
\text { Scale: } \quad 1: 30
\end{array}
$$

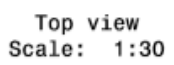

Gambar 2. Desain water cooling tank

Air yang ada dalam WCT terdiri dari 2 bagian air yaitu air primer yang berada di dalam pipa tembaga (sebagai heat exchanger) dan air sekunder yang berada di luar pipa tembaga (di kolam WCT. Untuk menganalisis kekuatan mekanik diperlukan sifat mekanik material yang akan digunakan sebagai salah satu data masukkan. Sifat mekanik Carbon Steel AISI 1040 yang digunakan sebagai material WCT ditunjukkan pada Tabel 1.

\begin{tabular}{lc} 
Tabel 1. Sifat mekanik bahan Carbon Steel AISI $1040[16]$ \\
\hline \multicolumn{1}{c}{ Sifat Mekanik } & Carbon Steel AISI 1040 \\
\hline Young Modulus & $2,10 \times 10^{11} \mathrm{~N} / \mathrm{m}^{2}$ \\
Poisson Ratio & 0,3 \\
Density & $7845 \mathrm{Kg} / \mathrm{m}^{3}$ \\
Thermal Expantion & $1,36 \times 10^{-5} 1 / \mathrm{K}$ \\
Yield Strength & $3,5 \times 10^{8} \mathrm{~N} / \mathrm{m}^{2}$ \\
\hline
\end{tabular}


Analisis kekuatan mekanik meliputi tegangan mekanik dan translational displacement dan tegangan mekanik yang diperoleh dari hasil analisis secara simulasi dibandingkan dengan yield strength material yang digunakan, sedangan translational displacement yang terjadi harus jauh lebih kecil dibandingkan dengan dimensi WCT.

\section{Tahapan Simulasi} berikut ;

Tahapan simulasi yang dilakukan dalam menganalisis kekuatan mekanik adalah sebagai

1. Pembuatan model 3-dimensi.

Pada tahapan ini dilakukan pembuatan model 3-dimensi WCT pada untai FASSIP-02 dengan mengacu pada desain. Model tersebut dilengkapi dengan sifat-sifat material yang digunakan pada desain dan digunakan sebagai data masukan.

2. Pembebanan.

Pembebanan maksimal yang diberikan pada WCT adalah berupa tekanan hidrostatis yang didapatkan melalui perhitungan dengan persamaan :

$$
p=\rho g h
$$

Sehingga didapatkan besar tekanan hidrostastis adalah

$$
p=1000\left(\mathrm{~kg} / \mathrm{m}^{3}\right) \times 10\left(\mathrm{~m} / \mathrm{s}^{2}\right) \times 2,75(\mathrm{~m})=27500\left(\mathrm{~N} / \mathrm{m}^{2}\right)
$$

Tekanan hidrostatis tersebut diasumsikan menekan secara merata pada kelima sisi dinding bagian dalam WCT. Beban variasi yang diberikan berupa variasi temperatur pada air sekunder WCT.

3. Restrain.

Restrain mensimulasikan model 3-dimensi WCT pada kondisi statis. Restrain harus diberikan pada model agar simulasi dapat dilakukan.

4. Pengujian tegangan mekanik.

Model 3-dimensi diberikan input berupa sifat-sifat material, beban dan restrain. Selanjutnya dilakukan simulasi untuk mengetahui besaran tegangan mekanik dan translasional displacement yang terjadi. Besaran tegangan mekanik dibandingkan dengan yield strength material yang digunakan sehingga dapat diketahui kekuatan mekanik desain WCT pada untai FASSIP-02.

\section{HASIL DAN PEMBAHASAN}

Analisis kekuatan mekanik pada desain WCT dengan beban berupa tekanan hidrostatis yang diasumsikan merata pada bagian dalam dinding WCT sebesar $p 27500 \mathrm{~N} / \mathrm{m}^{2}$ dengan temperatur air sekunder WCT sebesar $30^{\circ} \mathrm{C}$ ditunjukkan pada Gambar 3 dan Gambar 4.

Hasil analisis melalui pengujian secara simulasi mendapatkan kekuatan mekanik WCT untai FASSIP-02 pada Gambar 3 menunjukkan bahwa tegangan mekanik terbesarnya $5,21 \times 10^{7} \mathrm{~N} / \mathrm{m}^{2}$. Tegangan mekanik tersebut lebih kecil dari yield strength material yang digunakan $3,5 \times 10^{8} \mathrm{~N} / \mathrm{m}^{2}$ dan masih berada didaerah elastis masing-masing material. Sehingga jika beban berupa tekanan ditiadakan maka WCT akan kembali ke bentuk dan dimensi semula. 

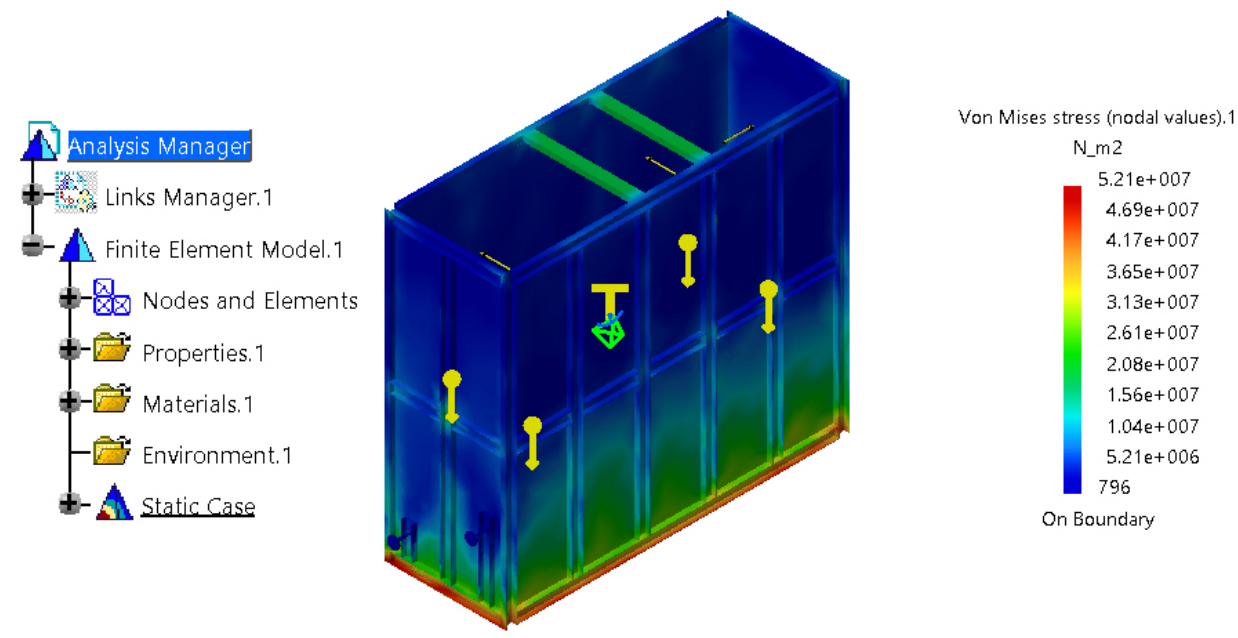

Gambar 3. Analisis tegangan mekanik pada WCT untai FASSIP-02
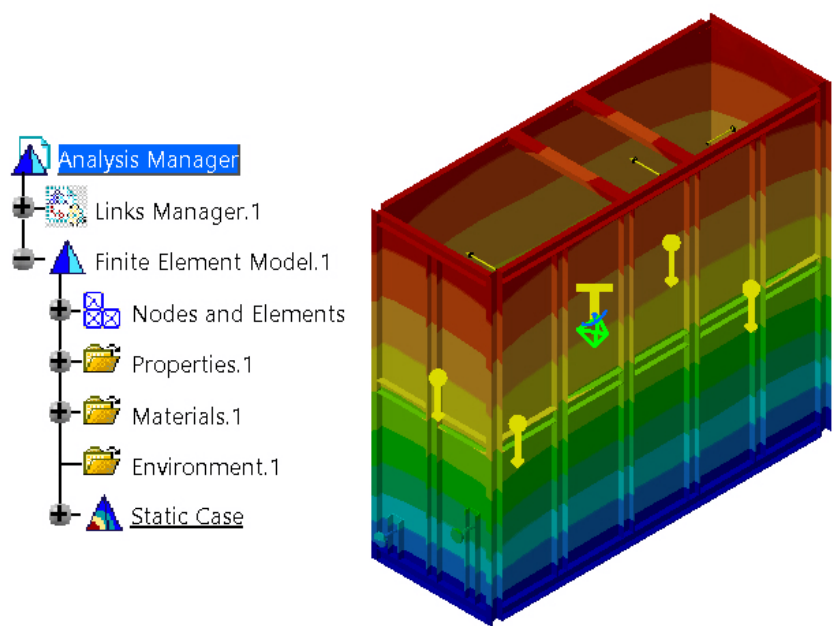

Translational displacement magnitude.1

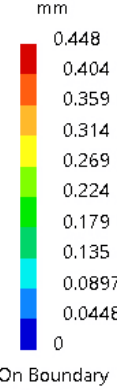

Gambar 4. Analisis Translational Displacement WCT FASSIP-02

Hasil translational displacement terbesar pada WCT FASSIP-02 ditunjukkan Gambar 4 sebesar 0,448 mm sangat kecil sehingga tidak merubah bentuk. Pengujian secara simulasi dengan memvariasikan temperatur air sekunder WCT bertujuan untuk mengetahui ketangguhan desain WCT. Variasi temperatur dimulai dari $30{ }^{\circ} \mathrm{C}$ sampai dengan $110{ }^{\circ} \mathrm{C}$ dengan kenaikan temperatur 20 ${ }^{\circ} \mathrm{C}$, hasil yang diperoleh ditunjukkan pada Tabel 2.

Tabel 2. Hasil pengujian secara simulasi pada WCT dengan memvariasikan temperatur air sekunder

\begin{tabular}{cccccc}
\hline No. & $\begin{array}{c}\text { Temperatur } \\
\left({ }^{\circ} \mathrm{C}\right)\end{array}$ & $\begin{array}{c}\text { Tekanan } \\
\left(\mathrm{N} / \mathrm{m}^{2}\right)\end{array}$ & $\begin{array}{c}\text { Tegangan Mekanik } \\
\left(\mathrm{N} / \mathrm{m}^{2}\right)\end{array}$ & $\begin{array}{c}\text { Yield strength } \\
\left(\mathrm{N} / \mathrm{m}^{2}\right)\end{array}$ & $\begin{array}{c}\text { Translational } \\
\text { Displacement }(\mathrm{mm})\end{array}$ \\
\hline 1. & 30 & $2,75 \times 10^{4}$ & $5,21 \times 10^{7}$ & $3,5 \times 10^{8}$ & 0,448 \\
2. & 50 & $2,75 \times 10^{4}$ & $1,56 \times 10^{8}$ & $3,5 \times 10^{8}$ & 1,360 \\
3. & 70 & $2,75 \times 10^{4}$ & $2,60 \times 10^{8}$ & $3,5 \times 10^{8}$ & 2,270 \\
4. & 90 & $2,75 \times 10^{4}$ & $3,65 \times 10^{8}$ & $3,5 \times 10^{8}$ & 3,180 \\
5. & 110 & $2,75 \times 10^{4}$ & $4,69 \times 10^{8}$ & $3,5 \times 10^{8}$ & 4,090 \\
\hline
\end{tabular}

Hasil pengujian secara simulasi dengan memvariasikan temperatur air sekunder seperti yang ditunjukkan pada Tabel 2, terlihat bahwa semakin tinggi temperatur air sekunder WCT maka tegangan mekanik dan translational displacement juga mengalami peningkatan. Saat temperatur air sekunder WCT mencapai $90{ }^{\circ} \mathrm{C}(363 \mathrm{~K})$ tegangan mekanik telah melewati yield strength material 
(seperti yang ditunjukkan pada Gambar 5), sehingga WCT telah mengalami deformasi atau perubahan bentuk.

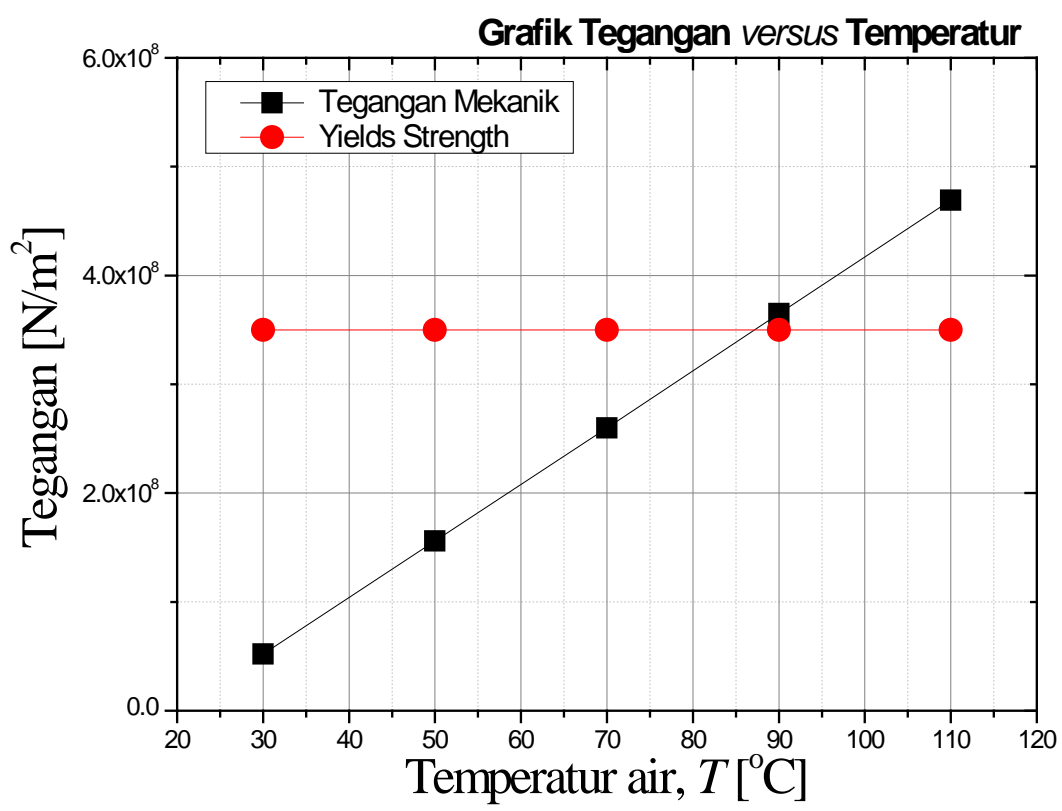

Gambar 5. Tegangan versus Temperatur pada uji Mekanik

Tetapi temperatur air sekunder atau air di WCT (kapasitas air sekunder di WCT 7500 liter) tidak akan mencapai temperatur sebesar $90{ }^{\circ} \mathrm{C}$ akibat pengambilan kalor pada air primer (kapasitas air primer di pipa tembaga WCT 2,13 liter). Hal ini dikarenakan untai FASSIP-02 dioperasikan dengan temperatur pada air primer maksimum $90{ }^{\circ} \mathrm{C}$. Dengan demikian desain WCT layak dikonstruksi dan aman digunakan sebagai salah satu komponen untai FASSIP-02.

\section{SIMPULAN}

WCT merupakan salah satu komponen untai FASSIP-02 yang berfungsi untuk mengambil kalor pada air primer. Hasil Analisis melalui pengujian secara simulasi mendapatkan tegangan mekanik pada WCT masih berada didaerah elastis material Carbon Steel AISI 1040 jika temperatur air sekunder di WCT kurang dari $90{ }^{\circ} \mathrm{C}$. Karena temperatur operasi pada air primer maksimal 90 ${ }^{\circ} \mathrm{C}$, maka temperatur pada air sekunder tidak akan mencapai $90{ }^{\circ} \mathrm{C}$. Sedangkan translational displacement yang terjadi sangat kecil jika dibandingkan dengan dimensi WCT sehingga tidak mengakibatkan perubahan bentuk pada WCT. Dengan demikian desain WCT dapat dilanjutkan untuk dikonstruksi dan aman dioperasikan.

\section{UCAPAN TERIMA KASIH}

Ucapan terima kasih disampikan kepada Kepala PTKRN BATAN dan Kepala BPFKR atas izin dan dukungannya. Terimakasih kepada dukungan Program Insinas Riset Pratama berjudul Pengembangan Sistem Pendingin Pasif Untuk Manajemen Kecelakaan Reaktor Nuklir Menggunakan Teknologi Heat Pipe dengan nomor kontrak 02/INS-2/PPK/E/E4/2017 tanggal 12 Juni - 8 Desember 2017 tahun anggaran 2017 serta tahun 2018 dalam pendanaan perjalanan dinas. Terimakasih disampaikan kepada teman-teman Subbidang Fasilitas Termohidrolika atas diskusi teknis yang dilakukan.

\section{DAFTAR PUSTAKA}

[1] Juarsa, M., dkk. (2011). Studi Eksperimental Laju Aliran Massa Air Berdasarkan Perubahan Sudut Kemiringan Untai Pada Kasus Sirklasi Alamiah Menggunakan Untai Sirklasi Alamiah 
(USSA-FT01). Jurnal Material dan Energi Indonesia, Jurusan Fisika FMIPA, Universitas Padjajaran, 1: p. 22-30.

[2] Antariksawan, A.R. (2000). Accident Analysis of PWR Station Blackout With Pump Seal Leak Using Melcor 1.8. 4.

[3] Kusuma, M.H., et al. (2017)., Simulation of Wickless-Heat Pipe as Passive Cooling System in Nuclear Spent Fuel Pool Using RELAP5/MOD3. 2. International Journal on Advanced Science, Engineering and Information Technology. 7(3): p. 836-842.

[4] Wang, M., et al. (2013)., An Evaluation Of Designed Passive Core Makeup Tank (CMT) For China Pressurized Reactor (CPR1000). Annals of Nuclear Energy,. 56: p. 81-86.

[5] Tjahjono, H. (2017)., Comprehensive Prediction of Thermosyphon Characteristics in Reactor Passive Cooling System Simulation Loop FASSIP-01. Atom Indonesia,. 43(3).

[6] Xiong, Z., et al. (2014), The Thermal Performance Of A Loop-Type Heat Pipe For Passively Removing Residual Heat From Spent Fuel Pool. Nuclear Engineering and Design,. 280: p. 262-268.

[7] Xiong, Z., et al. (2015)., Experimental Study On Heat Pipe Heat Removal Capacity For Passive Cooling Of Spent Fuel Pool. Annals of Nuclear Energy,. 83: p. 258-263.

[8] Ye, C., et al. (2013)., The Design And Simulation Of A New Spent Fuel Pool Passive Cooling System. Annals of Nuclear Energy,. 58: p. 124-131.

[9] Pinem, M.D. (2009)., CATIA Si Jago Desain Tiga Dimensi., Kawah Media, Jakarta.

[10] Haryanto;, D. And K. Santosa. (Bali, 15-16 Oktober 2015.)., Analisis Tegangan Mekanik Dan Translational Displacement Pada Struktur Experiment Kanal. in Seminar Nasional Teknologi Energi Nuklir 2015.

[11] Haryanto;, D., R. Djambiar;, And Sagino. (2014)., Analisis Rancangan Kit Holder Pada Mesin Universal Gerinding RUP/1500. in Seminar Penelitian Dan Pengelolaan Perangkat Nuklir Pusat Sain dan Teknologi Akselerator. 9 September 2014. Yogyakarta.

[12] Haryanto, D., et al. (2018), Analisis Kekuatan Mekanik Untuk Fasilitas Fase-Prhrs Menggunakan Perangkat Lunak Analisis Struktur. SIGMA EPSILON-Buletin Ilmiah Teknologi Keselamatan Reaktor Nuklir, 2018. 21(2).

[13] Antariksawan, A.R., et al. (2018)., Simulation Of Operational Conditions Of Fassip-02 Natural Circulation Cooling System Experimental Loop. Jurnal Sains dan Teknologi Nuklir Indonesia, 2018. 19(1): p. 40-52.

[14] Juarsa, M., et al. (2018)., Estimation Of Natural Circulation Flow Based On Temperature In The FASSIP-02 Large-Scale Test Loop Facility. in IOP Conference Series: Earth and Environmental Science. IOP Publishing.

[15] Antariksawan, A., et al. (2018)., Numerical Study On Natural Circulation Characteristics In FASSIP-02 Experimental Facility Using RELAP5 Code. in IOP Conference Series: Earth and Environmental Science. IOP Publishing.

[16] Properties of Carbon Steel AISI 1040. [cited 201810 March 2018]; Available from: http:// www.efunda.com/materials/alloys/ carbon_steels. 